\title{
The role of organic aerosols in homogeneous ice formation
}

\author{
B. Kärcher ${ }^{1}$ and T. Koop ${ }^{2}$ \\ ${ }^{1}$ DLR Oberpfaffenhofen, Institute for Atmospheric Physics, Wessling, Germany \\ ${ }^{2}$ University of Bielefeld, Faculty of Chemistry, Bielefeld, Germany \\ Received: 10 September 2004 - Published in Atmos. Chem. Phys. Discuss.: 20 October 2004 \\ Revised: 27 January 2005 - Accepted: 22 February 2005 - Published: 3 March 2005
}

\begin{abstract}
Recent field observations suggest that the fraction of organic-containing aerosol particles in ice cloud particles is diminished when compared to the background aerosol prior to freezing. In this work, we use model calculations to investigate possible causes for the observed behavior. In particular, homogeneous freezing processes in cooling air parcels containing aqueous inorganic particles and organic particles are studied with a detailed microphysical model. A disparate water uptake and resulting size differences that occur between organic and inorganic particles prior to freezing are identified as the most likely reason for the poor partitioning of organic aerosols into the ice phase. The differences in water uptake can be caused by changes in the relationship between solute mass fraction and water activity of the supercooled liquid phase, by modifications of the accommodation coefficient for water molecules, or by a combination thereof. The behavior of peak ice saturation ratios and total ice crystal number concentrations is examined, and the dependence of the results on cooling rate is investigated. Finally, processes are discussed that could possibly modify the homogeneous freezing behavior of organic particles.
\end{abstract}

\section{Introduction}

Atmospheric aerosols often consist of varying mixtures of organic and inorganic compounds (Duce et al., 1983; Saxena and Hildemann, 1996; Murphy et al., 1998). The organic species are found at times to account for up to $50 \%$ of the total dry aerosol mass in the boundary layer as well as the free troposphere (Novakov et al., 1997; Middlebrook et al., 1998; Murphy et al., 1998; Lee et al., 2002). Furthermore, in upper tropospheric aerosols the organics are usually internally mixed with sulfate, with organic constituents contributing $10-50 \%$ of the solute mole fraction (Murphy et al.,

Correspondence to: B. Kärcher

(bernd.kaercher@dlr.de)
1998; Lee et al., 2002). The chemical nature of these organics is quite diverse, but several field and modeling studies have suggested that dicarboxylic acids are a significant component of the organic fraction (Gill et al., 1983; Saxena and Hildemann, 1996; Chebbi and Carlier, 1996; Yao et al., 2002).

The possible impact of organic constituents on the interplay of atmospheric aerosol particles with water vapor and clouds has been investigated. For example, organics affect the hygroscopicity of aerosols (Cruz and Pandis, 2000; Dick et al., 2000; Ming and Russell, 2002) as well as the formation and properties of cloud droplets (Novakov and Penner, 1993; Facchini et al., 1999).

In contrast, the effects of organics on the ice nucleation behavior of upper tropospheric aerosols are less well studied. Some laboratory studies have indicated that homogeneous freezing of low molecular weight dicarboxylic acids is not as efficient as for sulfate aerosol, while others indicate identical ice nucleation efficiency (Prenni et al., 2001; Wise et al., 2004). Simultaneous measurements of ice cloud particles and chemical identification of aerosols have been made in the field (Cziczo et al., 2004a,b; DeMott et al., 2003). These measurements have revealed that organic-containing aerosols are less abundant than sulfate aerosols in ice cloud particles when compared to the interstitial aerosols, suggesting that organics might hamper ice nucleation. At present, the reason for this behavior is not clear. This uncertainty stems in part from the lack of molecular information on the organics that are contained in the observed aerosols.

Here, we present the first attempt to provide a basic theoretical understanding of the processes at work during the homogeneous formation of the ice phase in mixtures of inorganic and organic aerosols. To this end, we use a microphysical parcel model to study the effects of organics on homogeneous ice nucleation in liquid aerosols at upper tropospheric conditions as well as the resulting ice particle properties. We use a dicarboxylic acid, malonic acid ( $\left.\mathrm{HOOC}-\mathrm{CH}_{2}-\mathrm{COOH}\right)$, as a surrogate for the organics. In addition, we vary important

(C) 2005 Author(s). This work is licensed under a Creative Commons License. 
aerosol properties such as the mean particle size and water accommodation coefficient in order to make our results applicable also to other organics of atmospheric relevance.

\section{Model description}

\subsection{Microphysical model}

We use the detailed microphysical model APSC $m$ (Kärcher, 2003) to simulate aerosol particle growth and evaporation, homogeneous ice nucleation, ice particle growth and sublimation. The model is used in a parcel mode with prescribed constant cooling rates $d T / d t$.

Aerosol and ice particle size distributions are discretized over 100 size bins with a constant bin-volume ratio of 1.35 , starting at a minimum particle radius of $5 \mathrm{~nm}$. Aerosol growth is treated in a Lagrangian manner while ice particle growth is treated using a moving-center size structure that minimizes effects of numerical diffusion. Variable time steps inversely proportional to the cooling rate are sufficiently small (e.g., $0.1 \mathrm{~s}$ for $d T / d t=10 \mathrm{~K} \mathrm{~h}^{-1}$ ) to yield accurate numerical solutions.

Inorganic and organic particles are prescribed as distinct types and are distributed lognormally, each with a total number of $100 \mathrm{~cm}^{-3}$, a mode radius $R$ of $0.1 \mu \mathrm{m}$, and a geometric width of 1.5. These parameters are chosen such that most of the freezing particles are in the accumulation mode size range. This choice takes into account that atmospheric particles which have been chemically analyzed are $0.1-1 \mu \mathrm{m}$ in size. Much larger liquid particles do hardly exist in notable concentrations in the upper troposphere, while an aged accumulation mode is always present prior to cirrus cloud formation (Schröder et al., 2002). Smaller Aitken mode particles only have a chance to freeze homogeneously when this reservoir of larger particles is depleted. We are taking a lower limit concentration of free and upper tropospheric accumulation mode particles (typically several $100 \mathrm{~cm}^{-3}$ ), but observe in our calculations that crystal number densities are typically only a fraction of the total aerosol, consistent with observations.

For organic particles, the water accommodation coefficient $\alpha$ is varied, and for inorganic particles (assumed to consist of aqueous sulfuric acid, $\mathrm{H}_{2} \mathrm{SO}_{4} / \mathrm{H}_{2} \mathrm{O}$ ) we chose $\alpha=1$, which is consistent with recent laboratory measurements (Gershenzon et al., 2004). The ice mass deposition coefficient is set equal to 0.5 (Haynes et al., 1992). Lowering this value would lead to increases in the total number of ice particles and the peak ice saturation ratios in the freezing events, but would not change our conclusions. However, exceptionally low values for the water vapor deposition coefficient on ice as proposed by Gierens et al. (2003) would contradict recent field (Kärcher and Ström, 2003) and freezing chamber (Haag et al., 2003) measurements.
While for some applications we study the behavior of each particle type in isolation, we focus on the fraction $\eta$ of organic particles that contribute to the total number density $n_{i}$ of ice crystals formed.

To describe homogeneous ice nucleation and freezing of aqueous aerosols in the APSC $m$, we use the water-activitybased model by Koop et al. (2000). This model is based on an evaluation of ice nucleation measurements of 18 types of solutes including several organics. It has the advantage that it only requires knowledge of the water activity of a particular aerosol solution particle at any given temperature in order to calculate the corresponding ice nucleation rate coefficient, without the need to know the ice-solution surface tension and other quantities. (However, gas-solution surface tensions might affect the water activity of small droplets via the Kelvin barrier, and thus, indirectly, affect the freezing rate, see Sect. 3.4.) In the APSC $m$, the water activity is calculated for each aerosol type as as function of particle size.

In our model, ice nucleation is described as a volume dependent nucleation process. Recently, pseudo-heterogeneous surface nucleation of ice has been proposed as an alternative mechanism (Djikaev et al., 2002; Tabazadeh et al., 2002). We note that organics might also influence this ice nucleation process through changes in particle surface tension (Djikaev et al., 2004). However, because of the remaining uncertainties associated with the surface nucleation mechanism, we restrict our model calculations to homogeneous volume dependent nucleation of ice. With this nucleation model, the APSC $m$ has been shown to be suitable for the description of homogeneous freezing of sulfuric acid aerosol particles (Haag et al., 2003). In our present analysis, we make use of this model for all organic aerosols as well. Therefore, we can investigate what aerosol properties can lead to preferential ice nucleation of sulfuric acid over organic aerosols, even if the nucleation model is identical for both particle types.

In most simulations we use $d T / d t=10 \mathrm{~K} \mathrm{~h}^{-1}$, a value where non-equilibrium effects influence liquid aerosol water content and homogeneous freezing. Atmospheric observations suggest that such rapid cooling rates are caused by mesoscale variability in vertical wind speeds and occur rather frequently at mid- and low latitudes in cirrus conditions (Kärcher and Ström, 2003; Jensen and Pfister, 2004; Haag and Kärcher, 2004; Hoyle et al., 2005). However, we will also address the impact of smaller and higher cooling rates on our results.

The temperatures $T$ reported in this work are approximate freezing temperatures in the model, extending from warm $(230 \mathrm{~K})$ to cold $(200 \mathrm{~K})$ conditions. For simplicity, we let ice formation take place near an air pressure of $200 \mathrm{mb}$ in all cases. The direct effect of upper tropospheric pressure changes on homogeneous freezing temperatures in liquid aerosols is negligible for our study. Only a slight dependence is introduced in the particle growth laws through the molecular diffusivity. 
2.2 Representation of inorganic and organic aerosol properties

\subsubsection{General remarks}

We have chosen sulfuric acid and malonic acid as the representatives for inorganic and organic constituents of upper tropospheric aerosols. While the occurrence of $\mathrm{H}_{2} \mathrm{SO}_{4}$ is well established through field data (e.g., Murphy et al., 1998, and references therein), the chemical nature of organics found in upper tropospheric aerosols is less clear and still an open issue. As mentioned in Sect. 1, the organics will most likely consist of a distribution of several organic species. On the other hand, organic acids seem to constitute a major fraction of the organics (Gill et al., 1983; Saxena and Hildemann, 1996; Chebbi and Carlier, 1996; Yao et al., 2002).

Because of the lack of quantitative in situ data, we have tried to establish a realistic representation of organic constituents by carefully considering those properties which most likely affect the homogeneous ice freezing of aerosols under conditions of the upper troposphere: first, the thermodynamic properties of such aerosols and their equilibrium water uptake (hygroscopicity), and secondly, the kinetic water uptake through changes in the accommodation coefficient of water.

During the discussion phase of this paper the possible effects of changes in the liquid/gas surface tension has been mentioned. Such changes are considered very important for the activation of aerosols into clouds droplets in warm clouds (Facchini et al., 1999). However, the effect on ice freezing is less clear. In contrast to classical nucleation theory, changes in surface tension (either liquid/gas or ice/liquid) do not affect calculations with the water-activity-based ice nucleation model used in this study, which is independent of surface tension effects. In our calculations the solution surface tension only enters indirectly, through changes in the water uptake of small aerosols via the Kelvin effect (see discussion below).

\subsubsection{Equilibrium water uptake by organic aerosols}

Field measurements have shown that the hygroscopicity of ambient aerosols is affected by the presence of organics. For example, hygroscopicity tandem differential mobility analyzer data indicate that at low relative humidities the water content of aerosols containing organics is larger than that of sulfate aerosols. In contrast, at higher relative humidities the aerosols containing organics absorb considerably less water than sulfate aerosols (Dick et al., 2000). These observations can by generally understood by the thermodynamic properties of water soluble organic acids and their mixtures with inorganic salts, as confirmed by a large number of laboratory and theoretical studies (e.g., Cruz and Pandis, 2000; Peng et al., 2001; Choi and Chan, 2002a,b; Prenni et al., 2003; Ming and Russell, 2002; Marcolli et al., 2004). For example, at room temperature and a relative humidity of $80 \%$, the solute mass fraction of the inorganic solutes $\mathrm{H}_{2} \mathrm{SO}_{4}$, $\left(\mathrm{NH}_{4}\right)_{2} \mathrm{SO}_{4}$, and $\mathrm{NaCl}$ are about $0.27,0.43$, and 0.23 , respectively (Wexler and Clegg, 2002). These values are considerably smaller than those of various organic acids such as oxalic acid $(\sim 0.50)$, malonic acid $(\sim 0.54)$, succinic acid $(\sim 0.61)$, glutaric acid $(\sim 0.69)$, malic acid $(\sim 0.55)$, maleic acid $(\sim 0.60)$, citric acid $(\sim 0.62)$, and tartaric acid $(\sim 0.54)$ (Peng et al., 2001; Choi and Chan, 2002a,b). Mixtures of organic acids or other organic substances such as glycerol behave similarly (Choi and Chan, 2002a,b; Marcolli et al., 2004). This comparison shows that pure inorganic aerosol particles will contain more water than pure organic particles at high relative humidity conditions relevant to this study of homogeneous ice freezing.

In addition, internal mixtures of inorganic solutes such as $\left(\mathrm{NH}_{4}\right)_{2} \mathrm{SO}_{4}$ or $\mathrm{NaCl}$ with organic acids always led to a water uptake behavior (or particle growth factors) that was in between that of the pure components. Such experiments are consistent with calculations (Choi and Chan, 2002a; Ming and Russell, 2002; Prenni et al., 2003; Marcolli et al., 2004) which make use of the approach by Zdanovskii, Stokes, and Robinson (Seinfeld and Pandis, 1998).

Because of this more general pattern in the equilibrium water uptake behavior of the organic acids, we have decided to represent the organic hygroscopicity behavior of pure organic aerosols or mixed organic/inorganic aerosols by the thermodynamic properties of a single substance, malonic acid. We have chosen malonic acid for several reasons: first, it reveals a rather moderate hygroscopicity $(\sim 0.54$ at $80 \%$ $\mathrm{RH})$ that represents an intermediate value for the various acids discussed above; secondly, the thermodynamic properties of aqueous solutions of malonic acid at low temperature are better established than for most other organics of interest (Braban et al., 2003; Parsons et al., 2004); and thirdly, malonic acid is the smallest dicarboxylic acid with a large solubility in water, and it is miscible with inorganic solutes over a wide range of concentrations (Brooks et al., 2002; Ming and Russell, 2002; Wise et al., 2003; Marcolli et al., 2004).

In our simulations, we investigate three cases of aqueous solutions, pure aqueous sulfuric acid (SUL), pure aqueous malonic acid (ORG), and a 1:1 mole ratio mixture of sulfu$\mathrm{ric}$ acid/malonic acid (SUL/ORG). We frequently refer to the first type as "inorganic" and to the two latter types as "organic".

To perform simulations with such aerosols in the APSC $m$, the water vapor pressure of aqueous solutions of these solutes are required over a wide concentration range to low temperatures $(\sim 200 \mathrm{~K})$. The vapor pressure of $\mathrm{H}_{2} \mathrm{SO}_{4} / \mathrm{H}_{2} \mathrm{O}$ solutions has been calculated using the parameterization by Luo et al. (1995). Since neither data nor parameterizations exist for aqueous malonic acid solutions at low temperatures, we have used experimental data to develop such a parameterization. We have used the data by Peng et al. (2001) at room temperature to establish a solute mass fraction versus water activity relationship, and the data by Braban et al. (2003) to 

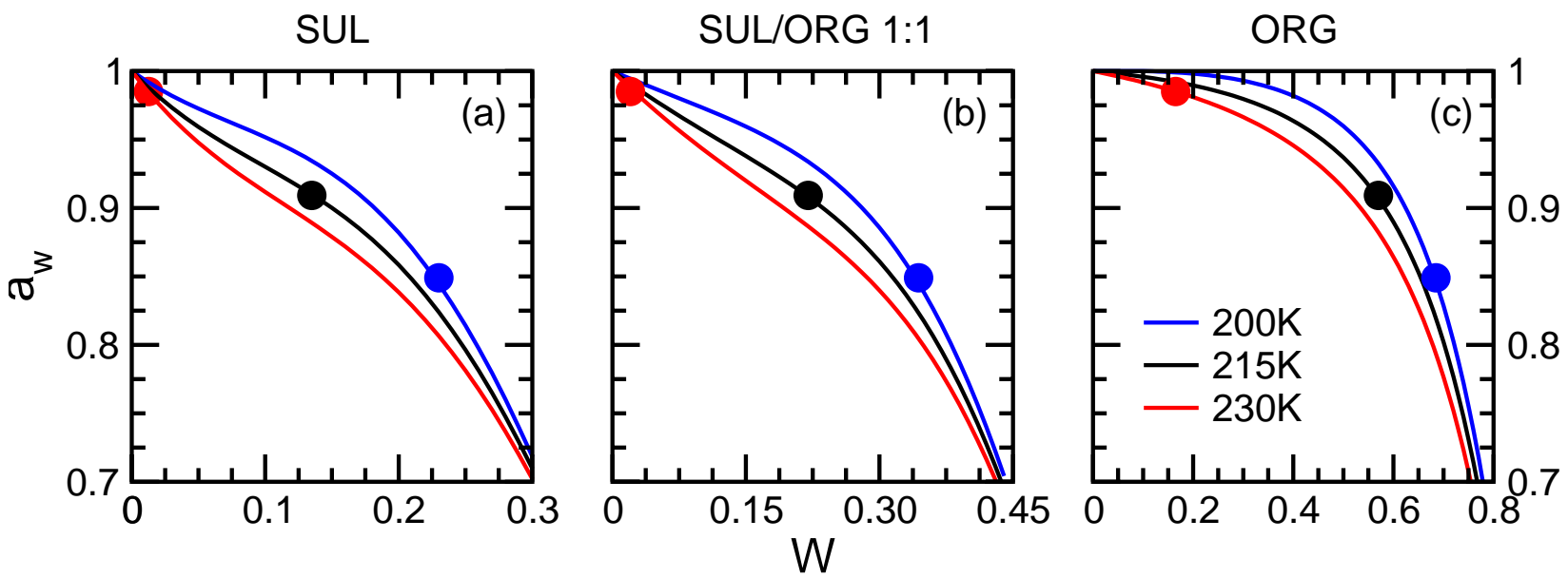

Fig. 1. Water activity as a function of solute mass fraction in aqueous solutions for three selected temperatures. Results are shown for pure sulfuric acid (a), a 1:1 molar mixture of sulfuric acid and malonic acid (b), and pure malonic acid (c). Throughout this work we use malonic acid as a surrogate for the thermodynamic behavior of water soluble organics, as discussed in Sect. 2.2.2. The filled circles indicate the conditions where homogeneous ice nucleation commences according to the water-activity-based freezing model, assuming that the freezing particles are in thermodynamic equilibrium with water vapor, i.e., $a_{w}=R H / 100 \%$. For any given $T$, freezing occurs at the same $a_{w}$ in each particle type, but the corresponding particle volumes $(\propto 1 / W)$ may differ significantly.

parameterize its temperature dependence for the extrapolation to low temperatures. The latter data are in agreement with very recent measurements by Parsons et al. (2004). We have used both pure binary parameterizations to calculate the water vapor pressure of mixed ternary aqueous solutions of sulfuric acid/malonic acid with a 1:1 solute mole ratio. This has been done using the approach by Zdanovskii, Stokes, and Robinson (Seinfeld and Pandis, 1998), which has been shown to work successfully in ammonium sulfate/malonic acid mixtures at room temperature (Choi and Chan, 2002a; Prenni et al., 2003). Finally, we have used the above solution vapor pressures in the limit of vanishing solute mass fractions to compute the vapor pressure of pure water and hence water activity for reasons of internal consistency.

In Fig. 1 we show the $a_{w}$ versus solute mass fraction $W$ relationships resulting from our calculations for pure aqueous sulfuric acid (SUL), the 1:1 sulfuric acid/malonic acid mixture (SUL/ORG), and pure aqueous malonic acid (ORG) at three different temperatures $T$ (color coded). The mixed particle type SUL/ORG interpolates between the pure components SUL (hygroscopic) and ORG (less hygroscopic); note that $W$-axis scales change. The filled circles (same color coding) indicate at which combination of $a_{w}$ and $W$ homogeneous freezing commences under equilibrium conditions based on the water activity model.

Finally, we note that we have performed similar calculations with polyols instead of malonic acid. The investigated polyols were oligomers of poly[ethylene glycol] with a molar mass of $300 \mathrm{~g} \mathrm{~mol}^{-1}$, PEG300. Although the quantitative results for the PEG300 system are slightly different, the key processes and pathways of freezing modification are very similar to the malonic acid system. This increases confidence in applying our findings to real atmospheric situations with variable types of organics, as described in Sect. 4.

\subsubsection{Water accommodation coefficient in organic aerosols}

The accommodation coefficient of water, $\alpha$, for the different solutions is unclear. While $\alpha=1$ is reasonable for aqueous sulfuric acid at low temperatures (Gershenzon et al., 2004; Clement et al., 1996), the presence of organic solutes might reduce $\alpha$ significantly (Gill et al., 1983; Wagner et al., 1996; Xiong et al., 1998).

The significant amounts of dissolved organics in our aerosol types ORG and SUL/ORG might also affect the value of $\alpha$ in such solutions. However, laboratory experiments indicate that already one or only a few monolayers of organics at the surface of an aerosol particle might affect $\alpha$ significantly (Xiong et al., 1998). Hence, only small amounts of a particular organic (or a mixture of organics) are sufficient to change $\alpha$, and even organics with a relatively low solubility in water or surface active compounds might affect $\alpha$. As a consequence, we believe that choosing only one representative value for $\alpha$ of organics is not a suitable approach for our purpose. Therefore, we have decided to treat $\alpha$ as a parameter in our simulations, and we vary $\alpha$ for the particle types ORG and SUL/ORG between 1 and $10^{-3}$ for all model runs. Here, small $\alpha$ values are considered to be the result of the combined effects of organics dissolved in the bulk and other organics located at the droplet surface (possibly only in low concentrations). 

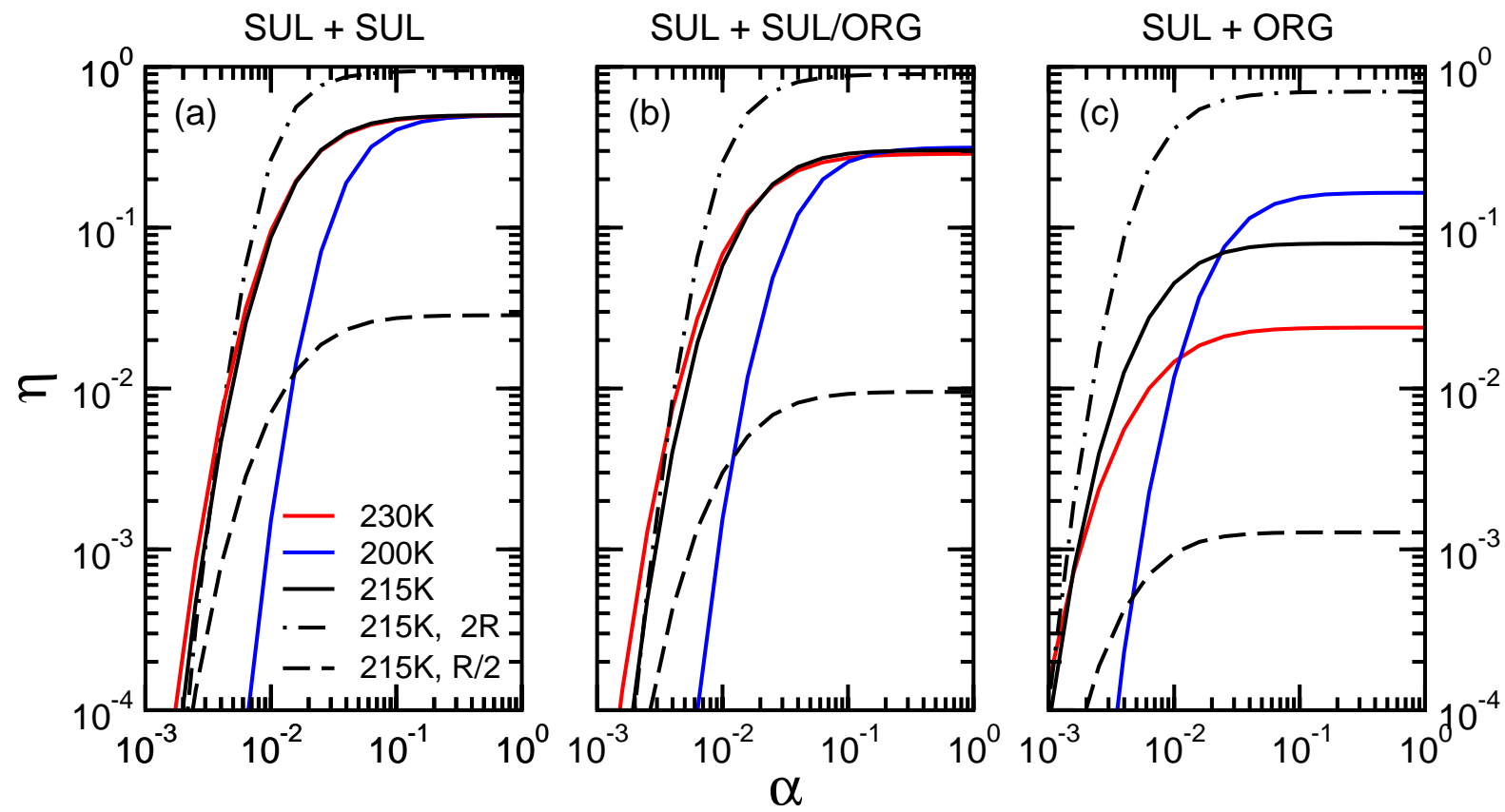

Fig. 2. Number of frozen aerosol particles with variable mass accommodation coefficient relative to the total number of ice particles formed in air parcels cooling at $10 \mathrm{Kh}^{-1}$ at different freezing temperatures. In all cases, the aerosol is composed of one pure inorganic particle mode (SUL) with $\alpha=1$, to which another inorganic mode (a), the internally mixed inorganic/organic mode (b), and a mode composed of pure organic (c) is added, each with variable $\alpha$. The solid curves represent cases where the initial dry size distribution of all modes were identical. The dashed (dash-dotted) curves represent cases where the initial dry sizes of the modes with variable $\alpha$ were half (twice) as large.

\section{Results and discussion}

\subsection{Aerosol composition affects particle size}

Let us first assume thermodynamic equilibrium between the ambient relative humidity $(R H)$ and the liquid aerosol particles at all times, i.e., $a_{w}=R H / 100 \%$. Then Fig. 1 tells us that the particles are less water-rich when the amount of organic solute is larger. Furthermore, the aerosol water content decreases with decreasing $T$. A direct implication of this behavior is that the organic-containing particles remain smaller in a cooling air parcel than the more hygroscopic sulfuric acid particles. This is consistent with laboratory measurements and thermodynamic modeling studies of other inorganic/organic mixtures, as discussed above. In addition, very small particles will have lower $a_{w}$ than larger ones owing to the Kelvin barrier (Seinfeld and Pandis, 1998; Haag et al., 2003).

On the other hand, also kinetic effects have an impact on the water content and $a_{w}$ of aerosol particles. For example, at low cooling rates, all particles will actually stay close to water equilibrium. However, very large particles will have lower $a_{w}$ than smaller ones due to diffusion limitations of the water condensation rate. The latter non-equilibrium effect becomes more important when the cooling rate is high and $T$ is low. Both, thermodynamic and kinetic effects have been modeled for aqueous sulfuric acid particles (Haag et al.,
2003), in close agreement with measurements (Möhler et al., 2003).

In sum, we emphasize that both, different thermodynamic properties of aerosol particles and kinetic effects are expected to result in a size separation between more and less hygroscopic particles that coexist in cooling air parcels. We demonstrate below that this size separation crucially impacts the contribution of each particle type to ice formation.

\subsection{Aerosol composition affects freezing fractions}

Next, we describe the results from the parcel simulations. In most of these simulations the aerosol is composed of two externally mixed modes with identical dry size distributions but distinct number concentrations. Each mode is allowed to have different hygroscopic properties and water accommodation coefficients. It is very instructive to study first two separate modes that both consist of $\mathrm{H}_{2} \mathrm{SO}_{4} / \mathrm{H}_{2} \mathrm{O}$ aerosols, with identical hygroscopic properties. However, we vary $\alpha$ from 0.0001 to 1 for one of the two modes for didactical purposes. Recall that $\eta$ is the fraction of frozen aerosol particles with variable $\alpha$ relative to the total number of frozen particles.

Figure 2a depicts the results for $\eta$ as a function of $\alpha$ for the two SUL modes (hereafter referred to as case SUL+SUL). As both aerosol modes have identical sizes (solid curves), $\eta=0.5$ when $\alpha$ approaches unity, because then both modes freeze in the same proportion. All solid curves in Fig. 2a would remain 


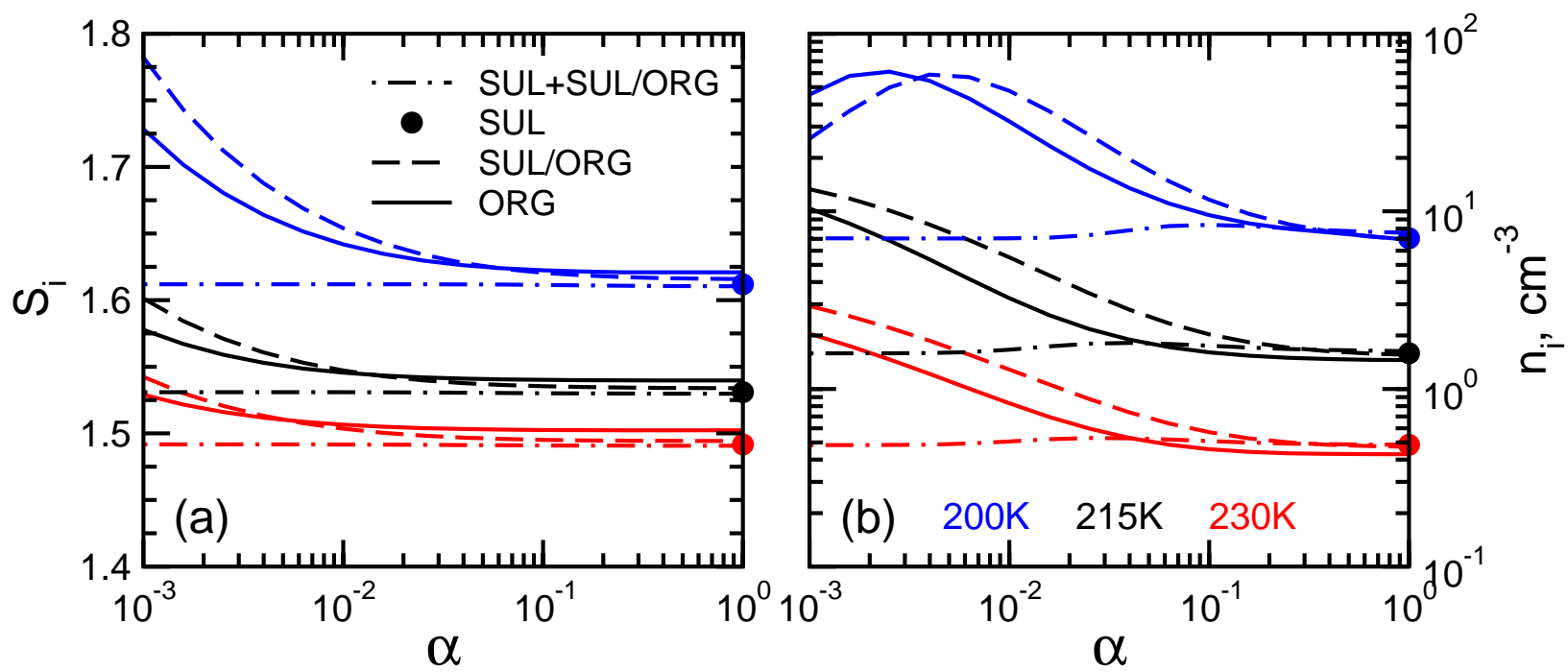

Fig. 3. Peak ice saturation ratio (a) and total number of ice crystals nucleated in the cooling air parcels as a function of the mass accommodation coefficient for pure inorganic particles (SUL, filled circles), pure organic particles (ORG, solid curves), internally mixed inorganic/organic particles (SUL/ORG, dashed curves), and the two particle system containing equal numbers of pure inorganic and internally mixed inorganic/organic particles (SUL+SUL/ORG, dash-dotted).

at $\eta=0.5$ for all values of $\alpha$ if the $\mathrm{H}_{2} \mathrm{SO}_{4} / \mathrm{H}_{2} \mathrm{O}$ particles were in full thermodynamic equilibrium at all times, in which case $a_{w}=R H / 100 \%$, regardless of size (apart from the Kelvin effect, which is unimportant in most of our simulations, confer Sect. 3.4).

However, fewer droplets freeze from the mode with reduced $\alpha$ because of reduced uptake of $\mathrm{H}_{2} \mathrm{O}$ molecules during the cooling phase. These particles are less dilute (lower $a_{w}$, higher $W$ ) and have smaller volumes than those with $\alpha=1$. This markedly reduces their probability to freeze homogeneously for $\alpha \lesssim 0.05-0.1$, depending on $T$. At low $T$, equilibrium is approached later, as the $\mathrm{H}_{2} \mathrm{O}$ vapor pressure decreases exponentially. (The characteristic timescale of equilibration of $\mathrm{H}_{2} \mathrm{O}$ by gas phase transport of $\mathrm{H}_{2} \mathrm{O}$ molecules to the aerosol particles is inversely proportional to the $\mathrm{H}_{2} \mathrm{O}$ vapor pressure.) For our choice of $d T / d t$, this effect becomes important only at $T<215 \mathrm{~K}$, as the red $(215 \mathrm{~K})$ and black $(230 \mathrm{~K})$ curves are almost identical. In Sect. 3.5 we will examine the role of $d T / d t$ in more detail.

We conclude from this exercise that non-equilibrium (kinetic) and size effects are intimately coupled. A size separation between particles with different water uptake properties must arise in a cooling air parcel. This size separation ultimately influences the freezing process even if the particle size distributions are identical prior to cooling.

The impact of initial differences in particle size is analyzed by discussing the dashed and dash-dotted curves in Fig. 2a, where we have increased and decreased $R$ from the particles with variable $\alpha$ by a factor of 2 , respectively, at $T=215 \mathrm{~K}$. More (fewer) of these droplets freeze when they are initially larger (smaller). The effect of initial differences in particle size is quite dramatic, and decides which of the two particle modes wins the freezing competition, regardless of $\alpha$. It is more pronounced at low $T$, where the kinetic effects are magnified. As shown at the end of this section, this effect occurs between chemically different aerosols as well.

Next, we investigate how differences in the hygroscopic properties of the two particle modes affect the water uptake, size, and freezing properties of the aerosol populations. In Figs. $2 \mathrm{~b}$ and $\mathrm{c}$, the second mode of particles with variable $\alpha$ are composed of the 1:1 mixture of sulfuric acid and organics (SUL/ORG) or pure organics (ORG), respectively, so that $\eta$ denotes the fraction of ice particles that nucleated on organiccontaining particles. The first mode continues to consist of aqueous sulfuric acid particles with $\alpha=1$.

The principal behavior $\eta(\alpha)$ for the organic cases is similar to case SUL+SUL, but we observe differences in detail which are caused by differences in $a_{w}$ between inorganic and organic species (recall Fig. 1). Typically, the organic aerosols do not freeze preferentially, as $\eta<0.5$ regardless of $\alpha$ or $T$ (solid curves). The computed $\eta$-values are not sensitive to $\alpha$ unless $\alpha \lesssim 0.05-0.1$, depending on $T$.

In contrast to case SUL+SUL, the solid curves differ in the limit $\alpha \rightarrow 1$, especially in case SUL+ORG, caused by the differences in hygroscopic properties of the particles. The case SUL+SUL/ORG can be considered as an intermediate case, in which the freezing properties are still largely dominated by $\mathrm{H}_{2} \mathrm{SO}_{4}$ in the mixed particles. The simulations start at water equilibrium, where the organic mass fraction $W$ adjusts such that $a_{w}(W, T)=R H / 100 \%$ for all droplets. As $W$ is inversely proportional to particle volume (apart from density effects), mean sizes of inorganic and organic droplets will be 
different inasmuch as their $a_{w}(W, T)$ are different. The organic particles are smaller than the $\mathrm{H}_{2} \mathrm{SO}_{4}$ particles (Fig. 1). This size effect becomes more pronounced as $T$ decreases and yields different $\eta$ in the limit $\alpha \rightarrow 1$.

The effect of initial size differences between SUL, SUL/ORG, and ORG particles are similar to Fig. 2a. We point out that the organic particles might freeze preferentially over $\mathrm{H}_{2} \mathrm{SO}_{4}$ when they are sufficiently large (dash-dotted curves in Figs. $2 \mathrm{~b}$ and c).

3.3 Aerosol composition affects freezing relative humidity and ice crystal concentrations

Figure 3a shows the peak saturation ratios over ice, $S_{i}$, for four cases (SUL, SUL/ORG, ORG, SUL+SUL/ORG) as a function of $\alpha$ and different freezing temperatures. Note that only the case SUL+SUL/ORG consists of two separate particle modes.

Peak values of $S_{i}$ are generally higher than the freezing onset values (not shown), the difference increasing with decreasing $T$, consistent with laboratory measurements and previous modeling studies (Möhler et al., 2003; Haag et al., 2003).

The SUL case with $\alpha=1$ is displayed with single filled circles. When organic solute is present (cases SUL/ORG and ORG), the peak (and onset) $S_{i}$ increases when $\alpha$ becomes smaller than $\sim 0.05-0.1$. For small $\alpha$, water uptake and, thus, freezing is retarded, allowing higher supersaturations to be reached. In such cases, the differences between onset and peak RHI can reach $8 \%$ (case ORG for $\alpha=0.001$ at $200 \mathrm{~K}$ ). An exception is the system SUL+SUL/ORG, where changes of $\alpha$ have no effect on $S_{i}$ which rather stays constant and close to the value obtained for case SUL. This is because ice formation occurs predominantly in the pure $\mathrm{H}_{2} \mathrm{SO}_{4}$ particles, see Fig. 2b, rendering the presence of externally mixed SUL/ORG particles unimportant for the freezing process.

An important atmospheric implication of these calculations is that the supersaturations required for homogeneous freezing of organic-rich particles can be substantially higher (by more than 0.1 ) than those for pure $\mathrm{H}_{2} \mathrm{SO}_{4} / \mathrm{H}_{2} \mathrm{O}$, but only in cases when no (or very few) separate $\mathrm{H}_{2} \mathrm{SO}_{4} / \mathrm{H}_{2} \mathrm{O}$ particles are available for freezing. For example, we find that less than $\sim 0.05 \mathrm{~cm}^{-3}$ SUL particles must be present in a SUL+SUL/ORG particle population (with $100 \mathrm{~cm}^{-3}$ SUL/ORG particles) at a freezing temperature of $200 \mathrm{~K}$ in order to obtain a peak value $S_{i}=1.78$ that coincides with the peak value obtained for pure SUL/ORG particles. The peak ice saturation is close to the pure SUL limit of $S_{i}=1.61$ in the same particle population when the concentration of SUL particles increases above $10 \mathrm{~cm}^{-3}$. We reiterate this issue in Sect. 4.

Figure $3 \mathrm{~b}$ shows the total number density of ice crystals, $n_{i}$, that nucleate from the aerosol types discussed in Fig. 3a. In general, $n_{i}$ increases with decreasing $T$ as growth rates of pristine ice particles are smaller at low $T$, causing a slower depletion of gaseous $\mathrm{H}_{2} \mathrm{O}$ and more available time for additional particles to freeze. Again, the filled circles denote the pure $\mathrm{H}_{2} \mathrm{SO}_{4} / \mathrm{H}_{2} \mathrm{O}$ case. For the organic particles SUL/ORG and ORG, $n_{i}$ starts to increase substantially when $\alpha<0.1$. At the coldest temperature, $n_{i}$ decreases again for $\alpha<0.006$ (SUL/ORG) or $\alpha<0.0025$ (ORG). Here, the water condensation rate onto aerosol particles becomes so small that only a limited number of particles can freeze, namely those large enough to take up water molecules despite the Kelvin barrier and small enough to take up water molecules despite diffusion limitations.

In contrast, the system SUL+SUL/ORG does not lead to significant changes of $n_{i}$, and the crystal concentration stays close to case SUL, except for a slight enhancement at $\alpha \sim 0.1$.

\subsection{Aerosol composition affects freezing aerosol size dis-} tributions

Interpretation of the results shown in Fig. 3 is supported by inspecting the freezing aerosol size distributions for selected cases, see Fig. 4. The freezing aerosol size distribution is defined as the difference between the aerosol number size distributions before and after freezing, displayed versus the dry particle diameter $D$.

The initial distributions are shown as black curves for the case SUL+SUL/ORG (left column), and for the cases SUL/ORG (middle column) and ORG (right column). The frozen particle distributions are plotted as solid curves (case SUL+SUL/ORG has two additive modes - solid curves: SUL, dashed curves: SUL/ORG). Also shown as filled circles are the freezing size distributions for case SUL (assuming $\alpha=1$ ) to guide the eye. As before, red curves are for $230 \mathrm{~K}$ and blue curves for $200 \mathrm{~K}$.

For the simulations with $\alpha=0.1$ (top panel in Fig. 4), freezing aerosol spectra are similar to the pure $\mathrm{H}_{2} \mathrm{SO}_{4} / \mathrm{H}_{2} \mathrm{O}$ case over a wide range of $T$. Only slight differences between SUL and SUL/ORG (middle column) and between SUL and ORG (right column) are notable. This is consistent with Fig. 3 when $\alpha>0.05$ (230 K) $\alpha>0.1$ (200 K), i.e., in regions where $S_{i}$ and $n_{i}$ do not change significantly.

We now consider the case $\alpha=0.001$ (bottom panel in Fig. 4), i.e., organic particles with a rather small water accommodation coefficient. If SUL and SUL/ORG are present as distinct particle types, then the organic particles do not contribute to freezing if $\alpha$ is small, and do not alter cirrus properties (left column).

However, the properties of cirrus clouds nucleating on organic particles SUL/ORG or ORG in the absence of SUL may strongly differ from pure SUL in terms of $S_{i}$ and $n_{i}$ for sufficiently small $\alpha$. Figure 4 demonstrates that the freezing aerosol distribution is shifted towards small particle sizes, where freezing at $200 \mathrm{~K}$ becomes eventually limited by the Kelvin effect, see left tails of the blue distributions in the cases SUL/ORG and ORG for $\alpha=0.001$. These results for low $\alpha$ and low $T$ are somewhat uncertain because, in the 


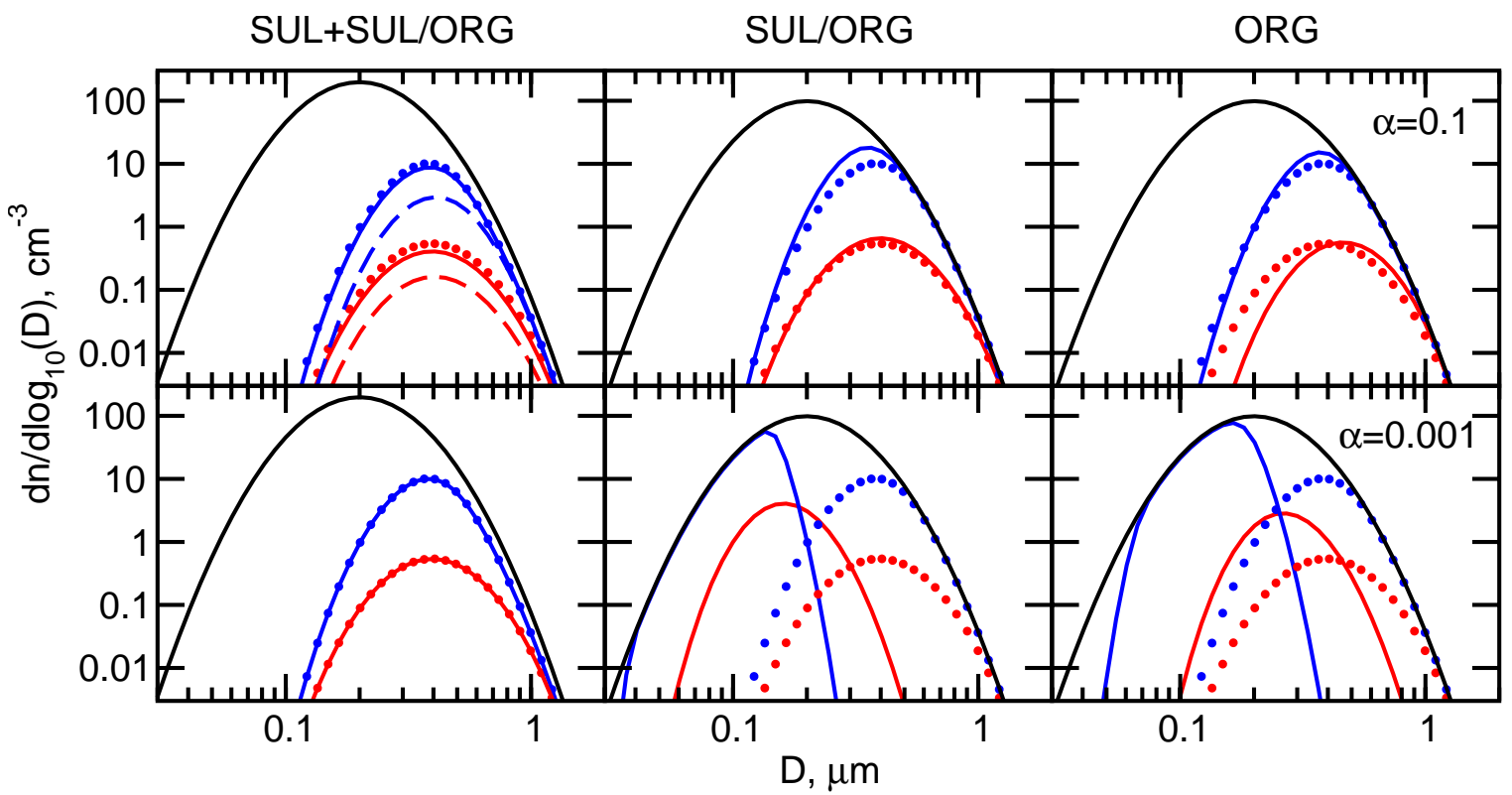

Fig. 4. Initial dry size distributions for the two particle system containing equal numbers of pure inorganic and internally mixed inorganic/organic particles (SUL+SUL/ORG), internally mixed inorganic/organicd particles only (SUL/ORG), and pure organic particles only (ORG), all shown as black curves. Results are given assuming $\alpha=0.1(\alpha=0.001)$ for SUL/ORG and ORG in the top (bottom) panel. As before, red (blue) curves denote freezing temperatures of 230 (200) K. The colored solid curves (including the dashed SUL/ORG contribution in the left column that contributes for $\alpha=0.1$ only) are the respective freezing aerosol distributions, defined as the difference of the distributions before and after freezing plotted versus dry particle size. In all figures the freezing distribution for case SUL (with $\alpha=1$ ) is shown (filled circles) for comparison.

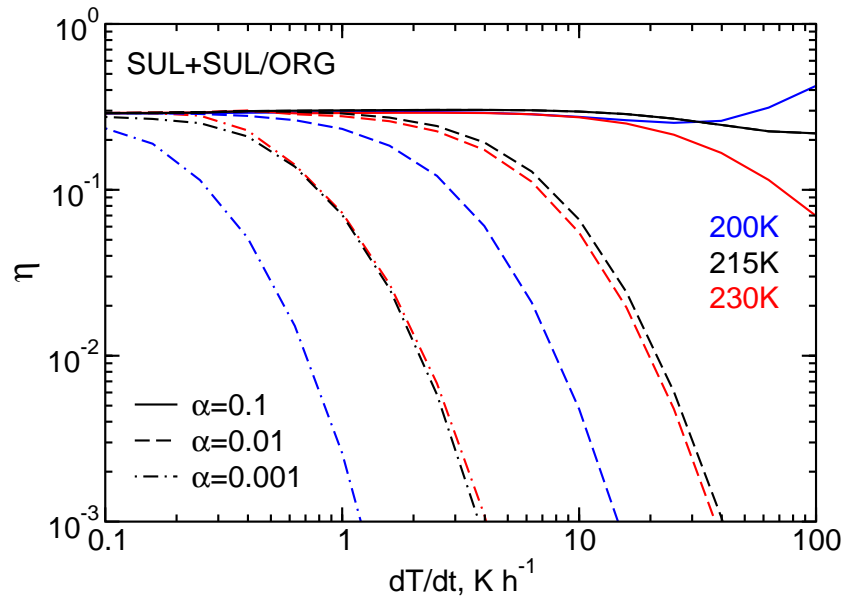

Fig. 5. Fraction of frozen aerosol particles in the two particle system SUL+SUL/ORG versus air parcel cooling rate for selected temperatures and mass accommodation coefficients of the SUL/ORG component.

absence of precise data, we have used the gas/liquid surface tension for $\mathrm{H}_{2} \mathrm{SO}_{4} / \mathrm{H}_{2} \mathrm{O}$ to calculate the Kelvin barrier for SUL/ORG and ORG.

In cases SUL/ORG and ORG, the large particles that freeze when $\alpha=0.1$ stay liquid when $\alpha=0.001$ at both temperatures, because diffusion of $\mathrm{H}_{2} \mathrm{O}$ molecules to them is hampered owing to strongly imperfect molecular accommo- dation at the particle surface. Delayed freezing occurs because smaller freezing particles result in smaller initial ice particles. Smaller ice particles, in turn, need longer to deplete the $\mathrm{H}_{2} \mathrm{O}$ gas phase and thereby shut off further nucleation. As a result, $n_{i}$ (and $S_{i}$ ) increases significantly over the SUL or SUL+SUL/ORG cases, as can also be read off Fig. 3.

\subsection{Effects of aerosol composition depend on cooling rates}

In Fig. 5 we show $\eta$ as a function of the adiabatic cooling rate for the two particle system SUL+SUL/ORG at selected $\alpha$ for the SUL/ORG particles and $T$. For $\alpha=0.1, \eta$ is a weak function of $d T / d t$ up to cooling rates of $\sim 20 \mathrm{~K} \mathrm{~h}^{-1}$. Under these conditions, all particles are close to water equilibrium, and $\eta \simeq 0.3$ is caused by differences in the equilibrium aerosol size distributions between SUL and SUL/ORG, see Fig. $2 b$. At higher cooling rates, non-equilibrium effects create larger differences in $\eta$, so that fewer organic-containing particles freeze for $T=215$ and $230 \mathrm{~K}$.

When $\alpha$ is decreased, the range of cooling rates $d T / d t$ within which all particles can be assumed to stay close to equilibrium conditions becomes successively narrower. Clearly, for less hygroscopic organic aerosols, the effect of disparate water uptake is the major factor for their poor homogeneous freezing potential for all conceivable values of $d T / d t$. 
Interestingly, the fraction of organic particles with $\alpha=0.1$ that freeze at $200 \mathrm{~K}$ increases at high cooling rates and approaches the limit $\eta=0.5$ (not shown). This is the case under conditions of vigorous cooling, where the freezing conditions are very rapidly surpassed and differences in freezing rates become irrelevant, thereby causing nearly all particles to freeze in the same proportion. This is not observed for smaller $\alpha$-values.

\section{Comparison with atmospheric observations}

A large body of mass spectrometric data of the composition of single particles obtained with the particle analysis by laser mass spectrometry (PALMS) instrument shows that organics are often internally mixed with sulfates (Murphy et al., 1998). The organic fraction varies significantly from almost pristine sulfate particles with only traces of organics to particles with comparable amounts of organic and inorganic species. In our theoretical two mode system SUL+SUL/ORG, SUL might represent particles with only a very small amount of water soluble organics, while SUL/ORG represents particles containing a significant water soluble organic mass fraction. The PALMS instrument does not distinguish between soluble and non-soluble organic species. While our choice SUL/ORG is consistent with these data, we cannot exclude that other possibilities exist as well.

Then, our finding that organic-containing aerosols are inefficient at homogeneous ice formation is consistent with more recent mass spectrometric measurements (Cziczo et al., 2004a,b; DeMott et al., 2003). In one study, particles from the clean lower troposphere over the continental United States of America were sampled and processed in the laboratory while in the second study particles were sampled and analyzed in situ in the subtropical upper troposphere.

On the basis of our model study, these new observations cannot be explained assuming only one internally mixed inorganic/organic particle mode with a fixed solute mole ratio.

Instead, the recent observations can be explained in terms of size differences between two distinct modes of inorganic $(\sim$ SUL) and mixed inorganic/organic $(\sim$ SUL/ORG) aerosol particles. The size effects arise either from initial differences in size distribution or from effects caused by differences in the thermodynamic and hygroscopic particle properties. Referring to Sect. 3.2, uncertainties in our simulations concern the size range over which most of the organic components are distributed and the chemical nature of the tropospheric organic aerosol population.

Atmospheric observations do not yet provide a detailed picture of the size-resolved chemical speciation of organiccontaining particles, as well as their mixing state with other particle types. This is why a closer comparison of our results with available observations is not possible at this point.
Our numerical simulations thus indicate the need for more specific data of such kind.

Ice saturation ratios up to 1.8 have been measured at cold temperatures (Gao et al., 2004) along with the presence of organic-containing particles (Cziczo et al., 2004b). In view of the results shown in Fig.3, if two distinct modes of the type SUL and SUL/ORG were present during these measurements, then the high $S_{i}$ values could only be explained if the number of SUL particles was exceptionally low $\left(<0.05 \mathrm{~cm}^{-3}\right.$ at $200 \mathrm{~K}$ according to the estimate given in Sect. 3.3) and the SUL/ORG particles had very low water accommodation coefficients (of the order 0.001). Additional mechanisms that, possibly in combination with the effects of organics discussed above, might generate high $S_{i}$ values include: small-scale temperature oscillations leading to larger peak values of $S_{i}$ (by 0.05-0.1 depending on the amount of ice present and on $T$ ), which are not considered in our calculations but may effect the measured $S_{i}$ values in the atmosphere (Kärcher and Haag, 2004); uncertainties at low $T$ in the parameterizations for the vapor pressures of ice and supercooled liquid water and their effect on calculated saturation ratios by perhaps $0.1-0.2$ in terms of $S_{i}$ (Murphy and Koop, 2005); effects of metastable cubic ice on the modeled gas phase relative humidities (Murphy, 2003).

\section{Conclusions}

The findings of our modeling study are summarized as follows. As before, we refer with "inorganic" to pure inorganic particles and with "organic" to either pure organic or internally mixed organic/inorganic particles.

1. Differences in the sizes of two externally mixed particle modes determine the homogeneous freezing fractions of each mode in a cooling air parcel. If the particles are chemically identical, the larger mode particles freeze first, preventing most of the smaller mode particles from ever nucleating ice. This effect is more pronounced the lower the freezing temperature.

2. If two particle modes have identical sizes, but differ chemically (inorganic versus organic particles), the particles from the organic mode tend to stay less water-rich during cooling and thus stay smaller than inorganic particles, even if the organic particles have high $(>0.1)$ water accommodation coefficients.

In conditions close to local water equilibrium (slow synoptic cooling), where the water activity in each particle is close to the ambient relative humidity, irrespective of its chemical nature, the organic aerosol is inefficient at homogeneous freezing owing to the induced size effects.

At higher cooling rates (e.g., during mesoscale gravity wave activity) particularly at low temperatures, nonequilibrium effects caused by (a) an increased time scale 
of water condensation, (b) diffusion limitation of water molecules to large particles $(>1 \mu \mathrm{m})$, and (c) the Kelvin effect for small particles $(<0.1 \mu \mathrm{m})$ all influence the freezing fraction of organic particles.

3. If organic particles are sufficiently larger than inorganic particles prior to cooling, it might happen that the organic mode particles nucleate ice preferentially over the inorganic mode, despite less efficient water uptake.

4. Besides size, the water accommodation coefficient for organic particles is a crucial factor controlling their ability to freeze homogeneously. Small values $(<0.1)$ slow the rates of increase of water activity and volume of the particles, and thus delay freezing relative to inorganic particles, even if organic particles are initially larger and/or cooling rates are slow.

5. In case of vigorous cooling (e.g., in a convective cloud), differences between the freezing rates of organic and inorganic particles caused by size or kinetic effects diminish, if water accommodation coefficients of organic particles are not substantially smaller than $\sim 0.1$. In such situations, nearly all particles freeze in the same proportion.

6. In the absence of inorganic particles, organic aerosol particles with low water accommodation coefficients will cause a substantial increase in the freezing saturation ratio at low temperatures (perhaps by up to $\sim 0.2$ ), accompanied by an increase in the total number of ice crystals formed. If inorganic particles are present and compete in the freezing process, freezing commences at values characteristic for the inorganic particles unless their number concentrations fall below a (small) critical value.

Recent tropospheric observations indicate that organic particles preferentially remain unfrozen. In view of the above findings, these observations would be consistent with freezing processes initiated in physically separate modes of inorganic and organic particles. Our study thus provides a consistent physical explanation within the framework of the water-activity-based nucleation model if such distinct particle modes were indeed present during the measurements. We find it encouraging that some of our results have been confirmed with the help of an independent microphysical model in the discussion stage of this paper (Murphy, 2004), increasing confidence in the robustness of our conclusions enumerated above.

Our study further indicates the strong need for more specific data, because current atmospheric measurements do not provide all of the details about the organic aerosol number and size, size-resolved chemical composition and hygroscopicity, and mixing state with inorganic species, required to better constrain the model simulations.
We have not considered possible mechanisms that could modify the freezing process in organic aerosol particles. Hydrophilic OH-groups of long chain alcohols could selfassemble into two dimensional crystal-like structures at the surface of aerosol droplets and perhaps lead to increased freezing temperatures, as observed for supercooled liquid water droplets of various size at rather warm temperatures (Gavish et al., 1990; Zobrist et al., 2004). On the other hand, as discussed in the present work, organic surfactants could hamper the uptake of water molecules in aerosol particles by reducing the water accommodation coefficient (e.g., Gill et al., 1983; Wagner et al., 1996; Xiong et al., 1998), thereby reducing their ability to freeze homogeneously.

Furthermore, partial crystallization in certain organic particles and delayed deliquescence could change the freezing mode from homogeneous to heterogeneous. The precipitated crystal, possibly an organic solid, might induce heterogeneous ice nucleation at the liquid/solid interface. Such effects have been observed in laboratory experiments with pure ammonium sulfate particles (Zuberi et al., 2001; Hung et al., 2002). Alternatively, ice nucleation might occur at the gas/solid interface in the deposition mode.

It is also possible that homogeneous freezing might be hampered in partially or fully crystallized particles. This would be the case, if the deliquescence relative humidity for the precipitate is larger than the relative humidity required for homogeneous ice nucleation of the fully liquid, but otherwise identical, particle. For partially crystallized particles, the reduced liquid volume would lead to a reduction in the actual nucleation rate, and for fully crystallized particles, homogeneous freezing would be switched off entirely. However, the latter case requires efflorescence of all individual solute species in a single aerosol particle. This appears to be somewhat unlikely when several solute species are involved, since the deliquescence relative humidity will also be reduced considerably (e.g., Marcolli et al., 2004).

Too little basic information is currently available to study all these issues theoretically. Despite these uncertainties, we believe that we have established the most important factors determining the role of organic tropospheric aerosols in homogeneous ice formation in cirrus conditions. In particular, we could show that preferential ice formation does occur even in the relatively simple homogeneous freezing framework using organic-containing, fully liquid particles. This may help refine parameterizations of cirrus cloud formation employed in climate models.

Our work provides a framework for future modeling studies of the formation of cirrus clouds by homogeneous freezing. More laboratory and field observations are required in order to make further headway in quantifying the overall role of organic aerosols including heterogeneous ice nuclei in the freezing process and assessing their impact on the tropospheric ice phase. 
Acknowledgements. This work was funded, in part, by the European Commission within the Integrated Project "StratosphereClimate Links With Emphasis on the UTLS" (SCOUT-O3).

Edited by: R. MacKenzie

\section{References}

Braban, C. F., Carroll, M. F., Styler, S. A., and Abbatt J. P. D.: Phase transitions of malonic and oxalic acid aerosols, J. Phys. Chem. A, 107, 6594-6602, 2003.

Brooks, S. D., Wise, M. E., Cushing, M., and Tolbert, M. A.: Deliquescence behavior of organic/ammonium sulfate aerosol, Geophys. Res. Lett., 29, 1917, doi:10.1029/2002GL014733, 2002.

Chebbi, A. and Carlier, P.: Carboxylic acids in the troposphere, occurrence, sources, and sinks: a review, Atmos. Environment, 30, 4233-4249, 1996.

Choi, M. Y. and Chan, C. K., The effects of organic species on the hygroscopic behaviors of inorganic aerosols, Environ. Sci. Technol., 36, 2422-2428, 2002a

Choi, M. Y. and Chan, C. K., Continuous measurements of the water activities of aqueous droplets of water-soluble organic compounds, J. Phys. Chem. A, 106, 4566-4572, 2002b.

Clement, C. F., Kulmala, M., and Vesala, T.: Theoretical considerations on sticking probabilities, J. Aerosol Sci., 27, 869-882, 1996.

Cruz, C. N. and Pandis, S. N.: Deliquescence and hygroscopic growth of mixed inorganic-organic atmospheric aerosol, Environ. Sci. Technol., 34, 4313-4319, 2000.

Cziczo, D. J., DeMott, P. J., Brooks, S. D., Prenni, A. J., Thomson, D. S., Baumgardner, D., Wilson, J. C., Kreidenweis, S. M., and Murphy, D. M.: Observations of organic species and atmospheric ice formation, Geophys. Res. Lett., 31, L12116, doi:10.1029/2004GL019822, 2004.

Cziczo, D. J., Murphy, D. M., Hudson, P. K., and Thomson, D. S.: Single particle measurements of the chemical composition of cirrus ice residue during CRYSTAL-FACE, J. Geophys. Res., 109, D04201, doi:10.1029/2003JD004032, 2004.

DeMott, P. J., Cziczo, D. J., Prenni, A. J., Murphy, D. M., Kreidenweis, S. M., Thomson, D. S., Borys, R., and Rogers, D. C.: Measurements of the concentration and composition of nuclei for cirrus formation, Proc. Natl. Acad. Sci., 100, 14 655-14 660, 2003

Dick, W. D., Saxena, P., and McMurry, P. H.: Estimation of water uptake by organic compounds in submicron aerosols measured during the Southeastern Aerosol and Visibility Study, J. Geophys. Res., 105, 1471-1479, 2000.

Djikaev, Y. S., Tabazadeh, A., Hamill, P., and Reiss H.: Thermodynamic conditions for the surface-stimulated crystallization of atmospheric droplets, J. Phys. Chem. A, 106, 10 247-10 253, 2002.

Djikaev, Y. S. and Tabazadeh, A.: Effect of adsorption on crystal nucleation in binary droplets: implication for the formation of nitric acid hydrate particles, J. Phys. Chem. A, 108, 6513-6519, 2004.

Duce, R. A., Mohnen, V. A., Zimmermann, P. R., Grojean, D., Cautreels, W., Chatfield, R., Jaenicke, R., Ogren, J. A., Pellizzari, E. D., and Wallace, G. T.: Organic material in the global troposphere, Rev. Geophys. Space Phys., 21, 921-952, 1983.
Facchini, M. C., Mircea, M., Fuzzi, S., and Charlson, R. J.: Cloud albedo enhancement by surface-active organic solutes in growing droplets, Nature, 401, 257-259, 1999.

Gao, R. S., Popp, P. J., Fahey, D. W., Marcy, T. P., Herman, R. L., Weinstock, E. M., Baumgardner, D. G., Garrett, T. J., Rosenlof, K. H., Thompson, T. L., Bui, T. P., Ridley, B. A., Wofsy, S. C., Toon, O. B., Tolbert, M. A., Kärcher, B., Peter, Th., Hudson, P. K., Weinheimer, A. J., and Heymsfield, A. J.: Evidence that ambient nitric acid increases relative humidity in low-temperature cirrus clouds, Science, 303, 516-520, 2004.

Gavish, M., Popovitz-Biro, R., Lahav, M., and Leiserowitz, L.: Ice nucleation by alcohols arranged in monolayers at the surface of water drops, Science, 250, 973-975, 1990.

Gershenzon, M., Davidovits, P., Williams, L. R., Shi, Q., Jayne, J. T., Kolb, C. E., and Worsnop, D. R.: Uptake of $\mathrm{H}_{2}{ }^{17} \mathrm{O}(\mathrm{g})$ and $\mathrm{D}_{2} \mathrm{O}(\mathrm{g})$ by aqueous sulfuric acid droplets, J. Phys. Chem. A, 108, 1567-1573, 2004.

Gierens, K., Monier, M., and Gayet, J.-F.: The deposition coefficient and its role for cirrus clouds, J. Geophys. Res., 108, 4069, doi:10.1029/2001JD001558, 2003.

Gill, P. S., Graedel, T. E., and Weschler, C. J.: Organic films on atmospheric aerosol particles, fog droplets, cloud droplets, raindrops, and snowflakes, Rev. Geophys. Space Phys., 21, 903-920, 1983.

Haag, W., Kärcher, B., Schaefers, S., Stetzer, O., Möhler, O., Schurath, U., Krämer, M., and Schiller, C.: Numerical simulations of homogeneous freezing processes in the aerosol chamber AIDA, Atmos. Chem. Phys., 3, 195-210, 2003,

SRef-ID: 1680-7324/acp/2003-3-195.

Haag, W. and Kärcher, B.: The impact of aerosols and gravity waves on cirrus clouds at midlatitudes, J. Geophys. Res., 109, D12202, doi:10.1029/2004JD004579, 2004.

Haynes, D. R., Tro, N. J., and George, S. M.: Condensation and evaporation of $\mathrm{H}_{2} \mathrm{O}$ on ice surfaces, J. Phys. Chem., 96, 8502-8509, 1992.

Hoyle, C. R., Luo, B. P., and Peter, T.: The origin of high ice crystal number densities in cirrus clouds, J. Atmos. Sci., in press, 2005.

Hung, H.-M., Malinowski, A., and Martin, S. T.: Ice nucleation kinetics of aerosols containing aqueous and solid ammonium sulfate particles, J. Phys. Chem. A, 106, 293-306, 2002.

Jensen, E. J. and Pfister, L.: Transport and freeze-drying in the tropical tropopause layer, J. Geophys. Res., 109, D02207, doi:10.1029/2003JD004022, 2004.

Kärcher, B.: Simulating gas-aerosol-cirrus interactions: Processoriented microphysical model and applications, Atmos. Chem. Phys., 3, 1645-1664, 2003,

SRef-ID: 1680-7324/acp/2003-3-1645.

Kärcher, B. and Ström, J.: The roles of dynamical variability and aerosols in cirrus cloud formation, Atmos. Chem. Phys., 3, 823 838,2003 ,

SRef-ID: 1680-7324/acp/2003-3-823.

Kärcher, B. and Haag, W.: Factors controlling upper tropospheric relative humidity, Ann. Geophysicae, 22, 705-715, 2004, SRef-ID: 1432-0576/ag/2004-22-705.

Koop, T., Luo, B. P., Tsias, A., and Peter, T.: Water activity as the determinant for homogeneous ice nucleation in aqueous solutions, Nature, 406, 611-614, 2000.

Lee, S. H., Murphy, D. M., Thomson, D. S., and Middlebrook, A. M.: Chemical components of single particles measured with 
Particle Analysis by Laser Mass Spectrometry (PALMS) during the Atlanta SuperSite Project: focus on organic/sulfate, lead, soot, and mineral particles, J. Geophys. Res., 107, 4003, doi:10.1029/2000JD000011, 2002.

Luo, B. P., Carslaw, K. S., Peter, T., and Clegg, S. L.: Vaporpressures of $\mathrm{H}_{2} \mathrm{SO}_{4} / \mathrm{HNO}_{3} / \mathrm{HCl} / \mathrm{HBR} / \mathrm{H}_{2} \mathrm{O}$ solutions to low stratospheric temperature, Geophys. Res. Lett., 22, 247-250, 1995.

Marcolli, C., Luo, B. P., and Peter, T.: Mixing of the organic aerosol fractions: liquids as the thermodynamically stable phases, J. Phys. Chem. A, 108, 2216-2224, 2004.

Middlebrook, A. M., Murphy, D. M., and Thomson, D. S.: Observations of organic material in individual marine particles at Cape Grim during the First Aerosol Characterization Experiment (ACE 1), J. Geophys. Res., 103, 16 475-16483, 1998.

Ming, Y. and Russell, L. M.: Thermodynamic equilibrium of organic-electrolyte mixtures in aerosol particles, AIChE J., 48, 1331-1348, 2002.

Möhler, O., Stetzer, O., Schaefers, S., Linke, C., Schnaiter, M., Tiede, R., Saathoff, H., Krämer, M., Mangold, A., Budz, P., Zink, P., Schreiner, J., Mauersberger, K., Haag, W., Kärcher, B., and Schurath, U.: Experimental investigations of homogeneous freezing of sulphuric acid particles in the aerosol chamber AIDA, Atmos. Chem. Phys., 3, 211-223, 2003,

\section{SRef-ID: 1680-7324/acp/2003-3-211.}

Murphy, D. M.: Dehydration in cold clouds is enhanced by a transition from cubic to hexagonal ice, Geophys. Res. Lett., 30, 2230, doi:10.1029/2003GL018566, 2003.

Murphy, D. M.: Interactive comment on: The role of organic aerosols in homogeneous ice formation by B. Kärcher and T. Koop, Atmos. Chem. Phys. Discuss., 4, S2299-S2300, 2004.

Murphy, D. M. and Koop, T.: Review of the vapour pressure of ice and supercooled water for atmospheric applications, Q. J. Roy. Meteor. Soc., in press, 2005.

Murphy, D. M., Thomson, D. S., and Mahoney, M. J.: In situ mesurements of organics, meteoritic material, mercury, and other elements in aerosols at 5 to 19 kilometers, Science, 282, 1664$1669,1998$.

Novakov, T. and Penner, J. E.: Large contribution of organic aerosols to cloud-condensation-nuclei concentrations, Nature, $365,823-826,1993$.

Novakov, T., Hegg, D. A., and Hobbs, P. V.: Airborne measurements of carbonaceous aerosols on the east coast of the United States, J. Geophys. Res., 102, 30 023-30 030, 1997.

Parsons, M. T., Mak, J., Lipetz, S. R., and Bertram, A. K.: Deliquescence of malonic, succinic, glutaric, and adipic acid particles, J. Geophys. Res., 109, D06212, doi:10.1029/2003JD004075, 2004.

Peng, C., Chan, M. N., and Chan, C. K.: The hygroscopic properties of dicarboxylic and multifunctional acids: measurements and UNIFAC predictions, Environ. Sci. Technol., 35, 4495-4501, 2001.
Prenni, A. J., DeMott, P. J., Kreidenweis, S. M., Sherman, D. E., Russell, L. M., and Ming, Y.: The effects of low molecular weight dicarboxylic acids on cloud formation, J. Phys. Chem. A, 105, 11 240-11248, 2001.

Prenni, A. J., DeMott, P. J., and Kreidenweis, S. M.: Water uptake of internally mixed particles containing ammonium sulfate and dicarboxylic acids, Atmos. Environment, 37, 4243-4251, 2003.

Saxena, P. and Hildemann, L. M.: Water-soluble organics in atmospheric particles: a critical review of the literature and application of thermodynamics to identify candidate compounds, J. Atmos. Chem., 24, 57-109, 1996.

Schröder, F. P., Kärcher, B., Fiebig, M., and Petzold, A.: Aerosol states in the free troposphere at northern midlatitudes, J. Geophys. Res., 107, 8126, doi:10.1029/2000JD000194, 2002.

Seinfeld, J. H. and Pandis, S. N.: Atmospheric Chemistry and Physics, John Wiley, New York, 1998.

Tabazadeh, A., Djikaev, Y. S., and Reiss H.: Surface crystallization of supercooled water in clouds, Proc. Natl. Acad. Sci., 99, $15873-15878,2002$.

Wagner, J., Andrews, E., and Larson, S. M.: Sorption of vapor phase octanoic acid onto deliquescent salt particles, J. Geophys. Res., 101, 19533-19540, 1996.

Wexler, A. S. and Clegg, S. L.: Atmospheric aerosol models for systems including the ions $\mathrm{H}^{+}, \mathrm{NH}_{4}^{+}, \mathrm{Na}^{+}, \mathrm{SO}_{4}^{2-}, \mathrm{NO}_{3}^{-}, \mathrm{Cl}^{-}, \mathrm{Br}^{-}$, and $\mathrm{H}_{2} \mathrm{O}$, J. Geophys. Res., 107, doi:10.1029/2001JD000451, 2002.

Wise, M. E., Surratt, J. D., Curtis, D. B., Shilling, J. E., and Tolbert, M. A.: Hygroscopic growth of ammonium sulfate/dicarboxylic acids, J. Geophys. Res., 108, 4638, doi:10.1029/2003JD003775, 2003.

Wise, M. E., Garland, R. M., and Tolbert, M. A.: Ice nucleation in internally mixed ammonium sulfate/dicarboxylic acid particles, J. Geophys. Res., 109, D19203, doi:10.1029/2003JD004313, 2004.

Xiong, J. Q., Zhong, M. H., Fang, C. P., Chen, L. C., and Lippmann, M.: Influence of organic films on the hygroscopicity of ultrafine sulfuric acid aerosol, Environ. Sci. Technol., 32, 35363541, 1998.

Yao, X. H., Fang, M., and Chan, C. K.: Size distributions and formation of dicarboxylic acids in atmospheric particles, Atmos. Environ., 36, 2099-2107, 2002

Zobrist, B., Luo, B. P., Marcolli, C., Peter, T., and Koop, T.: A conceptual model for ice nucleation of water samples in the presence of organic surfactants, in: Nucleation and Atmospheric Aerosols 2004, edited by: M. Kasahara and M. Kulmala, pp. 119-122, Kyoto University Press, Kyoto, 2004.

Zuberi, B., Bertram, A. K., Koop, T., Molina, L. T., and Molina, M. J.: Heterogeneous freezing of aqueous particles induced by crystallized $\left(\mathrm{NH}_{4}\right)_{2} \mathrm{SO}_{4}$, ice, and letovicite, J. Phys. Chem. A, 105, 6458-6464, 2001. 